Document downloaded from:

http://hdl.handle.net/10251/47577

This paper must be cited as:

Segura Garcia, J.; Giménez Pérez, A.; Romero Faus, J.; Cerdá Jordá, S. (2011). A comparison of different techniques for simulating and measuring acoustic parameters in a place of worship: Sant Jaume Basilica in Valencia, Spain. Acta Acustica united with Acustica. 97(1):155-170. doi:10.3813/AAA.918396.

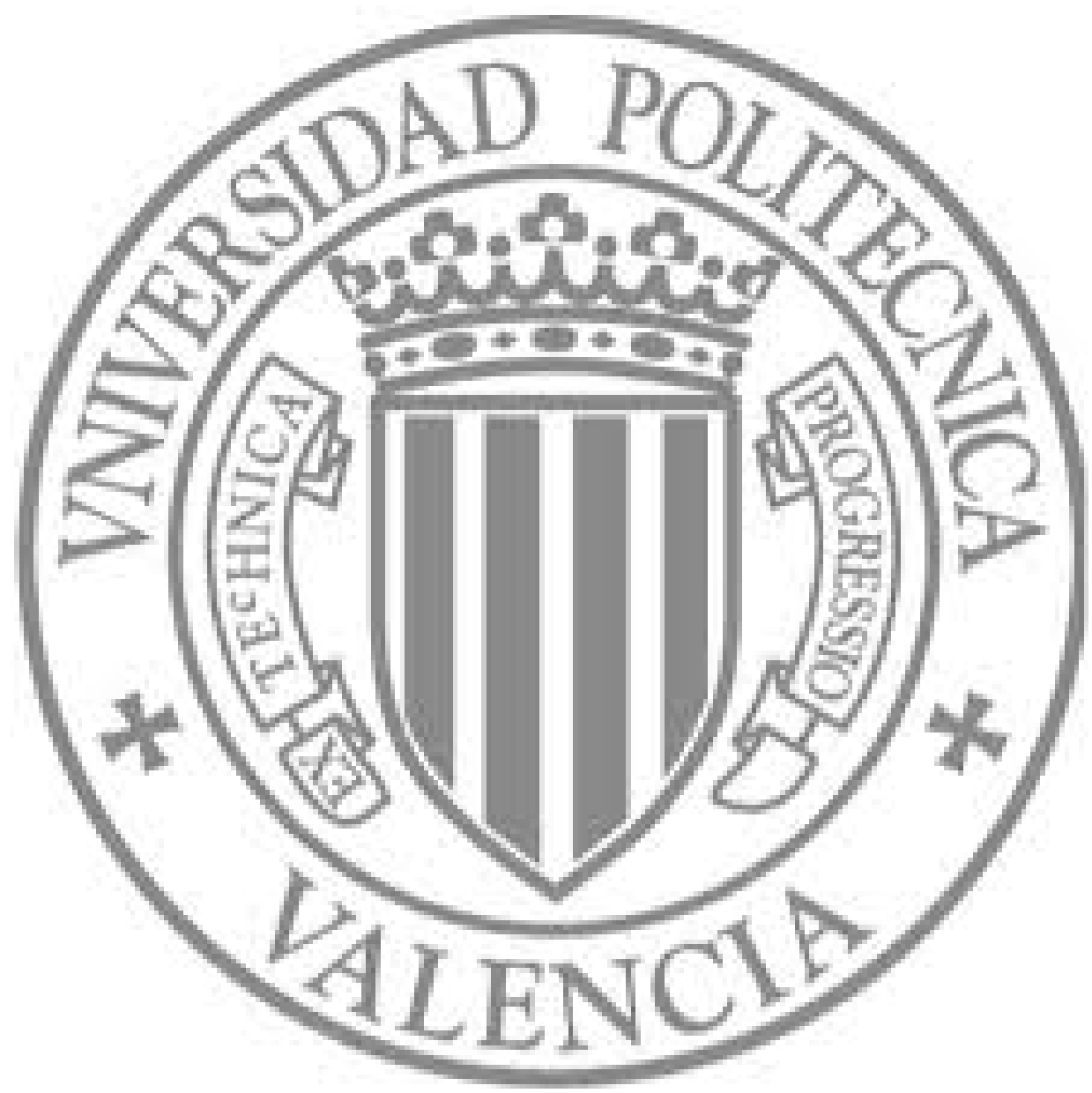

The final publication is available at

http://dx.doi.org/10.3813/AAA.918396

Copyright Hirzel Verlag (S. Hirzel Verlag) 


\title{
A Comparison of Different Techniques for Simulating and Measuring Acoustic Parameters in a Place of Worship: Sant Jaume Basílica in Valencia, Spain
}

\author{
Jaume Segura $^{1)}$, Alicia Giménez ${ }^{2)}$, José Romero ${ }^{2)}$, Salvador Cerdá3) \\ 1) Computer Science Department. University of Valencia. Polígon de la Coma s/n, 46980 - Paterna (Valencia), \\ Spain. jaume.segura@uv.es \\ 2) Applied Physics Department, Polytechnic University of Valencia, Camino de Vera s/n, 46022 Valencia, Spain. \\ agimenez@fis.upv.es,romerof@ fis.upv.es \\ 3) Applied Mathematics Department, Polytechnic University of Valencia, Camino de Vera s/n, 46022 Valencia, \\ Spain.salcerjo@mat.upv.es
}

\begin{abstract}
Summary
The study of rooms devoted to sound transmission has become a discipline in which all the fundamentals areas of current scientific research in acoustics converge. To demonstrate how this convergence arises in this work, we present a complete and detailed acoustics study of the Sant Jaume Basilica in Algemesí (Valencia, Spain), a building which has been declared a site of cultural interest. Starting from this overall perspective, the first part of this paper describes the features of the room studied (chosen for its complexity), the usual parameters for the analysis of room acoustics, and two measurement methodologies and two simulating methods widely used by the scientific community. Based on the theoretical results (obtained from modelling) and measurements following the recommendations of ISO 3382 Standard [1], we study the errors in 'just noticeable differences' in acoustic parameters that a listener may perceive. The aim of the study is to highlight the drawbacks and successes of the procedures used. From the perspective of comparing the results, the purpose of this study is not to assess the experimental procedures themselves or the modelling systems, but rather to demonstrate, using the four possible measurement-calculation combinations, whether the differences obtained between the theoretical values and experimental values are within a reasonable range of acceptability.
\end{abstract}

PACS no. 43.55.Gx, 43.55.Ka, 43.55.Mc

\section{Introduction}

The importance that acoustics have had, and continue to have, in places of worship [2] has driven the development of techniques for simulation of sound in rooms over the last century. In recent years these techniques have improved considerably and have enabled us to obtain more accurate results which more closely recreate real acoustic conditions in rooms $[3,4]$. Using physics techniques, as sound sources early studies used light for optical methods, electric sparks for ultrasonic methods, mechanical vibrators for ripple tanks and three dimensional scale models which work based on general similarity theory; this latter procedure is not economically viable for large rooms with complex geometry and adornment, since the scale factor must have a bearing on all sound transmission elements and physical construction of the scale model.

Received 7 July 2009,

accepted 20 September 2010.
The low cost and simple infrastructure of computer modelling methods [4], combined with the major advances in computers over recent years, have permitted the development of ever more efficient calculation algorithms. This began in 1967, but it was from 1990 onwards that their development was perfected and enabled sound propagation to be described in terms of waves or particles. Wave models such as Finite Element Method (FEM), Boundary Element Method (BEM) and FDTD (Finite Difference in Time Domain) work with the wave equation and provide very accurate results for single frequencies, but entail a high computing time cost for the large number of natural mode frequencies (increasing with frequency) and for resolving rooms which are complex in both their geometry and wall coverings [5].

In particle models, sound propagation is linked to particles travelling at the speed of sound and complying with the laws of optical geometry, a technique known as the "ray tracing model" $[6,7]$.The main algorithms developed for implementing acoustic energy inside a room are: the 
Ray tracing or Cone tracing Algorithm, the Image Sources Algorithm and the Hybrid Algorithms which combine the best features of both methods [4]. The unsatisfactory results initially obtained [8] due to the loss of the wave nature of the sound signal have been improved, in large part thanks to scatter field techniques which take into account the scattering properties of room materials and structures $[4,9,10]$. Ascertaining the real acoustic properties of the materials making up the room is sometimes difficult [11], and for this reason measuring its scatter coefficients $[12,13,14]$ in the laboratory, "in situ", in nonscatter field conditions [15], is the first line of research today [16]. Building very detailed geometric models does not guarantee greater accuracy in calculating the acoustic parameters if the acoustic features (absorption and scattering) of the materials used to build the model are not a close enough approximation. Simplified geometric models with accurate acoustic features give good results [17]. This method, which is also used for studying the propagation of electromagnetic waves, gives better results at mid-high frequencies, and its limitation for low frequencies is less relevant for the perception of speech and music.

Computer tools for simulating mid-high frequencies are useful for measuring acoustic parameters. Otherwise, all the research about uncertainties due to the lack of omnidirectionality of the sound source was carried out by measurement procedures (as it establishes the norm ISO 3382). However, recent investigations [18] have shown the usefulness of the modelling tools for studying the influence of the lack of omnidirectionality of the source for high frequencies when determining the acoustic parameters. This supposes that the study of this dependence in different localizations can be carried out with a considerable reduction in time and necessary resources.

For this paper, we worked with geometric simulation techniques using two commercially available pieces of software [19, 20]: EPIDAURE, which is based on separate ray tracing and image sources, and CATT-Acoustics, which is based on hybrid techniques. Different acoustic parameters have been calculated for both simulations and have been compared with the results for the church obtained using two measurement techniques [21, 22].

The relative error has been established for each of the measured (MLSSA and WinMLS) and simulated (CATT and EPIDAURE) parameters chosen. These results have been compared with the values of the indicators of the smallest difference perceivable by a hearer, the just noticeable difference, ('jnd'). By comparing these relative errors we have examined the trueness capacities of the measurement and simulation techniques employed.

In our case, the jnd is the minimum variation in the value of an acoustic parameter that a hearer may perceive. It must be pointed out that currently, since the first studies [23] of the jnd of fundamental parameters for hearing music, these indicators (for knowing the subjective perception caused by a variation in said parameter) have on the whole been accepted by the scientific community [24, 25]. However, there is no definitive consensus as to their val-

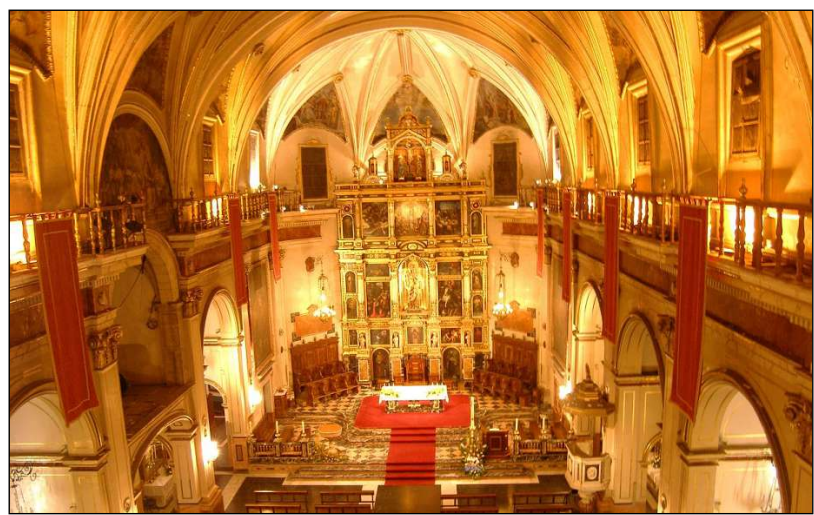

Figure 1. Sant Jaume Basílica.

ues $[26,27,28]$, or the different jnd values depending on frequency. The greatest jnd validity is at $1000 \mathrm{~Hz}$ and for parameter mean values [23]. The jnd for the parameters that reflect the tonal coloration (bass ratio and brilliance) has still to be discussed fundamentally.

\subsection{Modelled and studied room}

The room modelled is the Sant Jaume Basilica in Algemesí (Valencia) [29], declared a Building of Cultural Interest [30]. This was selected for study for two main reasons: the complexity of its geometry and its twin use for transmitting speech and listening to music. It is in the Baroque style and was built in the second half of the 16th century (1550-1582). The main body is divided into two areas, the apse nave with two side corridors which lead on to various small chapels (Figure 1).

The central nave measures $800 \mathrm{~m}^{2}$. Total volume is around $15000 \mathrm{~m}^{3}$. The approximate capacity of the church is 600 persons in the pews, but since the church is used for religious ceremonies and music concerts (organ recitals, choral singing, orchestral performances etc.), the audience may number over 1000 . Measurements were taken in the central nave given that most of the ecclesiastical and musical events are held here.

\subsection{Acoustic parameters}

The first stage in this study was to select and calculate a set of target parameters, and the mean values for both frequencies and locations of these parameters, the so-called 'merit figures' for comparing the results given by measurement and computer simulation. To make a selection, we chose the minimum set of common parameters in both simulation programs that can be measured experimentally by the two measuring systems. Binaural parameters were not used, because they cannot be calculated using EPIDAURE.

The parameters studied, grouped according to main subjective sensations [31, 32, 33, 34, 35, 36, 37] were:

- Reverberation parameters: $T R_{30}$ and, EDT (Reverberation Times), $B R$ (Bass Ratio), $B r$ (Brilliance).

- Energy parameters: $G$ (Strength), $C_{50}$ (Clarity for speech), $C_{80}$ (Clarity for music) and $T_{s}$ (Center Time). 
- Intelligibility parameters: STI.

These parameters are associated with the main subjective qualities of the halls:

- REVERBERATION: represents the degree of vivacity of the hall.

- TRANSPARENCY: as regards hearing music, transparency refers to the perception of separate tones in time and instruments played simultaneously.

- INTELLIGIBILITY: this parameter is essential for hearing speech and quantifies speech comprehension.

This point of view [38], seems to reflect the consensus that has been agreed in the current version of ISO 33821:2007 standard. All the obtained acoustic parameters of the measurements have been calculated using only WinMLS. In this way, it was possible to avoid the possible differences produced by different algorithms and only the transmission-acquisition process is compared.

\subsubsection{Reverberation Parameters}

Reverberation times $E D T$ and $T_{30}$ were calculated shown below. $E D T$ is the $60 \mathrm{~dB}$ decay time calculated by a line fitted to the portion of the decay curve between 0 and $-10 \mathrm{~dB} . T_{30}$ is the $60 \mathrm{~dB}$ decay time calculated by a line fitted to the portion of the decay curve between -5 and $-35 \mathrm{~dB}$. We worked with mid values and the Bass Ratio $(B R)$ and Brilliance $(B r)$ following [31]:

$$
\begin{aligned}
& T R_{\text {mid }}=\frac{1}{2}\left(T R_{30}^{500 \mathrm{~Hz}}+T R_{30}^{1 \mathrm{KHz}}\right), \\
& E D T_{\text {mid }}=\frac{1}{2}\left(E D T^{500 \mathrm{~Hz}}+E D T^{1 \mathrm{KHz}}\right), \\
& B R=\frac{T R_{30}^{125 \mathrm{~Hz}}+T R_{30}^{250 \mathrm{~Hz}}}{T R_{30}^{500 \mathrm{~Hz}}+T R_{30}^{1 \mathrm{KHz}}} \\
& B r=\frac{T R 30^{2 \mathrm{kHz}}+T R 30^{4 \mathrm{kHz}}}{T R 30^{500 \mathrm{~Hz}}+T R 30^{1 \mathrm{KHz}}}
\end{aligned}
$$

\subsubsection{Energy parameters}

The Strength Factor $G$ calculation equation is

$$
G=10 \log \frac{\int_{0}^{\infty} p^{2}(t) \mathrm{d} t}{\int_{0}^{\infty} p_{A}^{2}(t) \mathrm{d} t}, \quad \mathrm{~dB},
$$

where $p_{A}(t)$ is the free-field sound pressure level at a distance of $10 \mathrm{~m}$ [34]. We used direct sound as reference. Comparison with properly calibrated measurements has demonstrated that this method will normally provide $G$ values at low frequencies that are too high due to insufficient window length, fairly good $\mathrm{G}$ values at mid frequencies $(500-1000 \mathrm{~Hz})$, and $G$ values at high frequencies that are too low due to the influence of the immediate surroundings of the transducers [21]. The Clarity Factors $C_{50}$ and $C_{80}$ are given by

$$
C_{x}=10 \log \frac{\int_{0}^{x} p^{2}(t) \mathrm{d} t}{\int_{x}^{\infty} p^{2}(t) \mathrm{d} t}, \quad \mathrm{~dB},
$$

Center time $T_{s}$ is calculated as follows:

$$
T_{s}=\frac{\int_{0}^{\infty} t \cdot p^{2}(t) \mathrm{d} t}{\int_{0}^{\infty} p^{2}(t) \mathrm{d} t}, \quad \mathrm{~ms} .
$$

We worked with the averages given by $[34,39,40]$

$$
\begin{aligned}
G_{\text {mid }}= & \frac{1}{2}\left(G^{500 \mathrm{~Hz}}+G^{1 \mathrm{KHz}}\right), \\
C_{50}= & 0.15 \cdot C_{50}^{500 \mathrm{~Hz}}+0.25 \cdot C_{50}^{1 \mathrm{KHz}} \\
& +0.35 \cdot C_{50}^{2 \mathrm{kHz}}+0.25 \cdot C_{50}^{4 \mathrm{kHz}}, \\
C_{80}= & \frac{1}{3}\left(C_{80}^{500 \mathrm{~Hz}}+C_{80}^{1 \mathrm{KHz}}+C_{80}^{2 \mathrm{kHz}}\right) .
\end{aligned}
$$

We worked with center time at $1 \mathrm{kHz}$ band.

\subsubsection{Intelligibility parameters}

We worked with STI and RASTI from the original versions [41] which are based on weighted sums of modulation transfer function (MTF) values. STI is calculated as the weighted sum of modulation transfer indices MTI, one for each octave frequency band from $125 \mathrm{~Hz}$ through $8 \mathrm{kHz}$ (where each MTI value is derived from MTF values over 14 different modulation frequencies) taking into account auditory effects according to IEC 60268-16. The RASTI is calculated as the weighted sum of MTI's over the 500 and $2000 \mathrm{~Hz}$ octave bands, where the MTI values are derived from MTF values over 4 and 5 different modulation frequencies respectively. For the calculation of the parameters of speech in WinMLS we have used the default option that disregards the influence of background noise and masking effects (considering only reflections and decay).

\section{Room acoustics measurement procedure}

The experimental methodology used complies with the requirements of ISO-3382 [1] and IEC 60268 [42]. This section describes the technical features of the equipment used to measure the parameters derived from the impulse response described in section 1.2, systems for generating and emitting the excitation signal and its capture and analysis.

\subsection{Emission signal}

A linear time-constant system is characterized by its impulse response, since the transfer function is the Fourier transformation of this response and contains all the information on the transmission of the signal in the hall. Among the most commonly used, and the ones used for this work, are: Maximum Length Sequence, MLS, and sweep (sinusoidal sweep).

The MLS technique uses a pseudo-random binary sequence as excitation, whose self-correlation function corresponds to a Dirac delta $\left(R_{x x}(t) \simeq \delta(t)\right)$. The crosscorrelation of any signal with $\delta(t)$ is the signal itself, which means that:

$$
R_{x y}(t) \simeq \delta(t) * h(t)=\int h(\tau) \delta(t+\tau) \mathrm{d} \tau=h(t) .(11
$$


Therefore, in a linear system, if we calculate the crosscorrelation between the MLS signal applied to the input and the signal recorded at the output, we can determine the impulse response of this system and thus calculate its transfer function by means of applying the FFT.

The sweep technique uses a sinusoidal function whose frequency is a function of time from $20 \mathrm{~Hz}$ to $20 \mathrm{kHz}$. This frequency increase by unit of time may be constant over the duration of the sweep (linear) or may increase exponentially (logarithmic). Given the logarithmic behavior of the auditive response, this latter technique is more relevant for acoustic applications. Using this technique, the time of the excitation signal can be reduced with regard to the MLS. The advantage of sweep over MLS is that information on the harmonic distortion of the signal can be obtained from the measurement.

\subsection{Experimental equipment}

2.2.1. Excitation signal generation and emission system Using the types of signal indicated requires a generation algorithm and electro-acoustic devices to amplify and emit these signals. The signal amplification and emitter system comprises a PC with suitable software installed, professional sound card, an amplifier and a dodecahedric source.

Power amplifier M-1000 (Power output level RL=4: $520 \mathrm{~W}+520 \mathrm{~W}$ ). Its high power enables us to minimize the effect of background noise. With a total harmonic distortion of less than $1 \%$ and a signal/noise relationship of $100 \mathrm{~dB}$, it has a flat frequency response $( \pm 0.5 \mathrm{~dB}$ between $10 \mathrm{~Hz}$ and $35 \mathrm{kHz}$ ).

The dodecahedral loudspeaker DO12 (Rated power $600 \mathrm{~W}$, Sound Power $>120 \mathrm{~dB}$, Frequency range: $80 \mathrm{~Hz}-$ $6.3 \mathrm{kHz}$, directivity: nearly spherical)

\subsubsection{Capture, recording and analysis system}

The capture system comprises a laptop computer with capture and analysis software installed, a professional sound card and microphones.

The sound card (Vxpocket v2) is connected via Type II card. It has two mono-balanced analogue inputs with 24 bit converters and a sampling frequency of up to $48 \mathrm{kHz}$. This allows a flat frequency response to be obtained from $20 \mathrm{~Hz}$ to $20 \mathrm{kHz}$ with an accuracy of $\pm 0.15 \mathrm{~dB}$ and a signal/noise relationship of $94 \mathrm{~dB}$.

For measuring the monaural parameters, we used GRAS Type 40 AK microphones (Sensitivity at $250 \mathrm{~Hz}$ $50 \mathrm{mV} / \mathrm{Pa}$, Frequency Response (dB): $3.15 \mathrm{~Hz}-20 \mathrm{kHz}$, Upper Limit of Dynamic Range (3\% Distortion): $164 \mathrm{~dB}$ re. $20 \mu \mathrm{Pa}$, Lower Limit Dyn. range: $14 \mathrm{~dB}$, re. $20 \mu \mathrm{Pa}$ ).

The power source was GRAS 12AA which polarizes the microphones with a voltage of $200 \mathrm{~V}$, and GRAS preamplifiers Type $26 \mathrm{AK}$ (Frequency Range: $2 \mathrm{~Hz}-20 \mathrm{kHz}$, Noise: A-weight $:<2.5 \mu \mathrm{V})$.

We used the WinMLS and the MLSSA programs for measuring and WinMLS for analysis, WinMLS with multi-sweeps as the excitation signal and MLSSA with MLS (different excitation signals are used to report this possibility). These programs give the acoustic parameters of

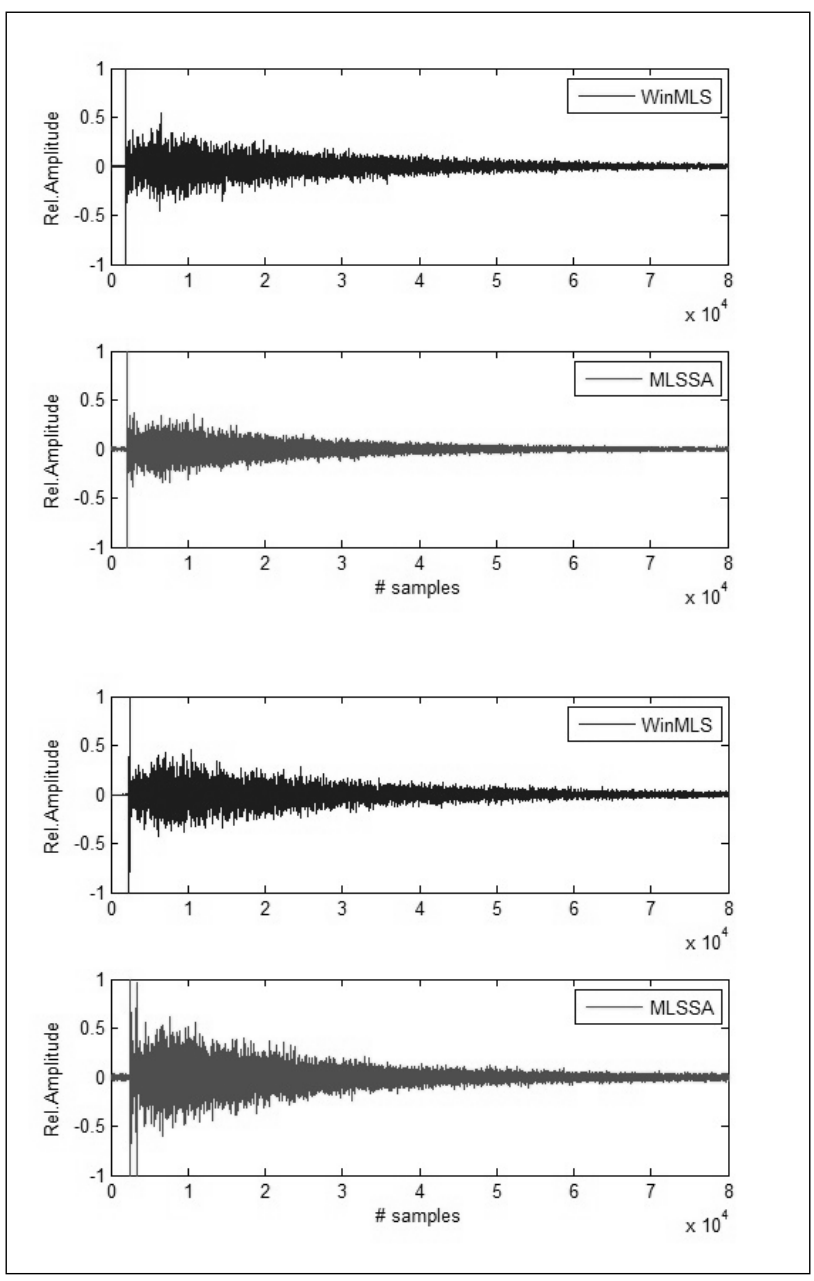

Figure 2. 'Measured IR at points 15 and 19, showing the validity of both SNR criteria'.

impulse response in accordance with the ISO 3382 Standard [1] and other recent parameters which were not included in the Standard, such as strength, (G), using direct sound as a reference. With this experimental device, the measurements were consecutively obtained using the software programs. At each measuring point, the signal transmission and reception connections were alternatively connected to each of the computers containing the WinMLS and MLSSA programs. In this way, it was possible to ensure that the direction of the transmission source and positioning of the measuring points was exactly the same for both methodologies.

In this respect, de Vries [28], reported that if the measurement setup for a source-receiver combination is altered by just a few centimeters when interchanging the source or microphone then measurable differences in the filtered impulse responses occur.

Following the recommendations of norm ISO 3382, the relationship $S / N>45 \mathrm{~dB}$ for all the frequencies has been adjusted in WinMLS for the time of signal transmission. For measurements with MLS, the signal has been transmitted at more than $15 \mathrm{~dB}$ above the background noise in accordance with the generally accepted protocol (see Figure 2). 


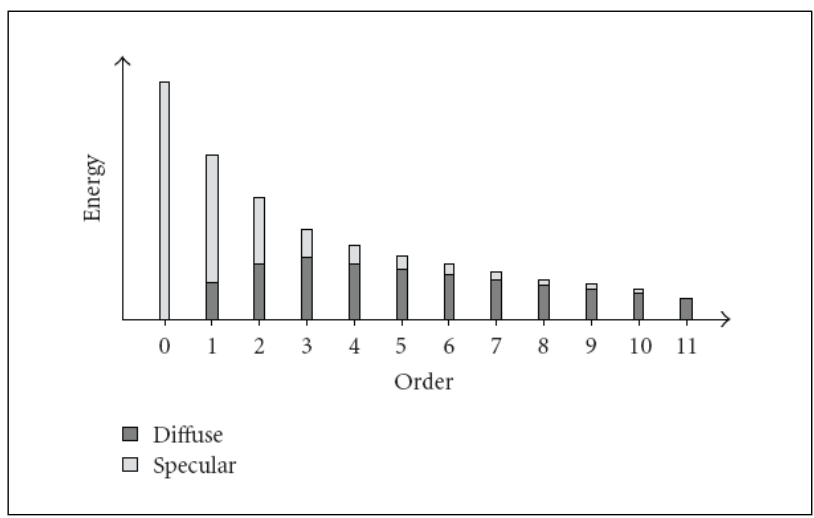

Figure 3. 'Ratio of specular to scattered energy received by reflection order'

\section{Room acoustics simulation}

For this study a geometric model was used to simulate the room. The methods used to do this were: ray tracing/cone tracing and image sources.

The commercial software used for the simulations was EPIDAURE [20] and CATT-Acoustics [19]. The EPIDAURE software uses both ray tracing and image sources for calculating the acoustic parameters of the room.

The user can specify which method to use. The CATTAcoustics software combines the geometric methods of cone tracing and image sources.

Ray tracing algorithms take into account that a wave coming from the source can be linked to a ray, cone or pyramid by means of the eikonal equation. The source statistically emits a series of rays with an specific energy which is lost with each reflection on incidence with the surfaces of the walls which delimit the geometric model. In our case, both of the calculation programs used take into account specular and diffuse reflections. In the case of CATT, the diffuse reflections are calculated from the explicit parametrization of the absorption and scattering parameters of each surface. In the case of EPIDAURE, these are carried out based on the definition of the reflection order in the calculation of the echograms.

Both procedures are justified for this type of low absorption room. According to the results obtained by Kutruff, as shown in Figure 3, the energy contribution for diffusion and reflection is equivalent to a high order of reflection (the results can be obtained using an average uniform absorption coefficient of 0.2 ). In this way, CATT directly includes the diffusion coefficients, while EPIDAURE introduces the corrections defining the reflection order.

It is necessary to indicate that for low absorptions, the parameter values are more sensitive to slight changes of absorption than to strong variations of diffusion coefficients for the same absorption. This has been confirmed by simulations made in a rectangular room. This simulation involved varying the mean absorption coefficient by between 6.8 and $7.95 \%$ by changing the materials; and substantially varying the Lambert diffusion coefficient between 30 and 90 by changing the roughness. The variation observed in $E D T$, for a given average absorption and using various diffusions, ranges from thousandths of a second to some hundredths of a second - according to the position. However, for the limits of absorption in the indicated range, a much greater variation takes place in the temporary parameter (of the order of tenths of a second).

For high absorption rooms, a more detailed knowledge of the behavior of the room is necessary. The diffusivity of the sound field depends on important factors such as the shape of the room, volume, absorption situation, and the adequate selection of diffusion coefficients [43] . A poor adjustment of these coefficients can produce erroneous results and experience reveals that mixed models must be used to obtain good results $[44,45,12]$.

The simulation process of the software used can be summarized into a number of points:

- Room geometry file. In this stage the features of the room are modelled, both in terms of geometry and the acoustic behavior of the materials making it up. The geometric model is constructed from the plans. The acoustic properties of the room are specified by the absorption and scattering coefficients.

- Receiver file. This is where information on the receivers in the room is stored, specifying their coordinates, acoustic reception features and orientation. This file is only used in CATT, since EPIDAURE includes the receivers by default.

- Emitter file. This contains information on the emitters in the room: position coordinates, orientation, emission level by octave bands, directivity pattern, delays for electro-acoustic sources, etc. This file is only used in CATT, since EPIDAURE includes the emitters by default. For simulating the source, we chose an omnidirectional spherical point source.

\subsection{Geometric modelling of the Basilica}

A model of the basilica was generated using the two aforementioned simulation programs. This model was implemented by defining 1314 surfaces. The model was made using the plans available: floor plan from 1985 and section and floor plans from 2000, and completed by taking measurements of details not included in the plans [29].

The source used for the simulation is located at point $(43,10.6,3.2)$ of the church space, being a site located 2 $\mathrm{m}$ in front of the altar. 24 receivers were distributed around the audience area (apse nave) (Figure 4).

\subsection{Materials}

Basic materials were used in this simulation. Given the impossibility of determining acoustic characteristics in the laboratory, the absorption coefficients for frequencies from 125 to $4000 \mathrm{~Hz}$ were obtained from the programs' own libraries. Likewise, in the case of CATT, scattering coefficient of 0.1 was used for all frequencies although more research would be required to obtain these coefficients in rooms of similar characteristics. In view of the size of the 
Table I. Absorption coefficients for materials and air.

\begin{tabular}{|c|c|c|c|c|c|c|c|}
\hline Material & Area $\left(m^{2}\right)$ & $125 \mathrm{~Hz}$ & $250 \mathrm{~Hz}$ & $500 \mathrm{~Hz}$ & $1000 \mathrm{~Hz}$ & $2000 \mathrm{~Hz}$ & $4000 \mathrm{~Hz}$ \\
\hline Wall plastering & 8565.95 & 0.120 & 0.100 & 0.070 & 0.090 & 0.070 & 0.050 \\
Marble & 2164.58 & 0.010 & 0.010 & 0.010 & 0.020 & 0.020 & 0.010 \\
Pine wood & 98.67 & 0.098 & 0.110 & 0.061 & 0.081 & 0.082 & 0.110 \\
Ord. wood & 525.29 & 0.100 & 0.160 & 0.130 & 0.100 & 0.060 & 0.050 \\
Light felt & 180.57 & 0.020 & 0.040 & 0.100 & 0.210 & 0.570 & 0.920 \\
Stone & 356.52 & 0.010 & 0.012 & 0.020 & 0.020 & 0.023 & 0.035 \\
Air (dB/100m) & & 0.037 & 0.121 & 0.284 & 0.504 & 0.999 & 2.806 \\
\hline
\end{tabular}

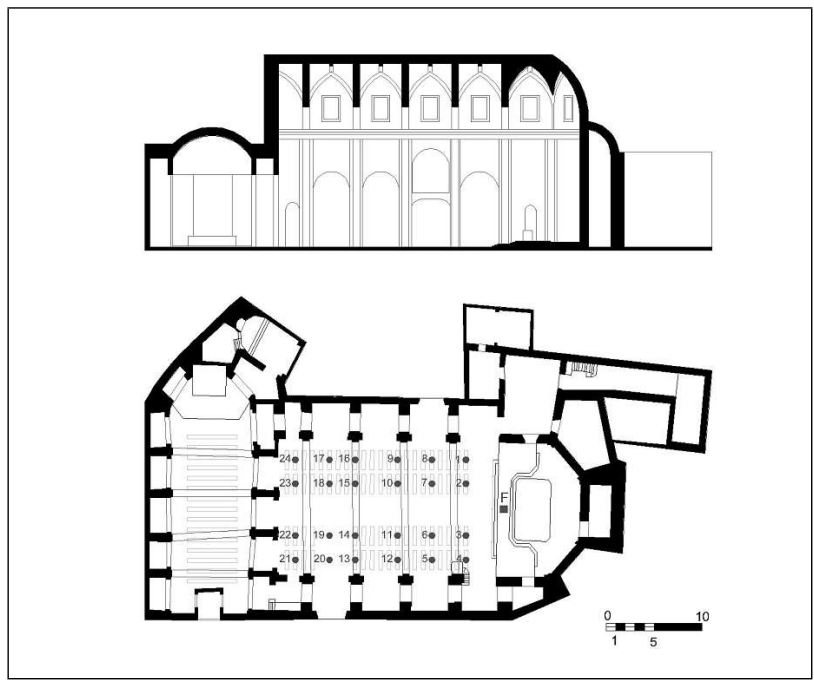

Figure 4. Section and floor of the Basílica.

church, environmental conditions and air absorption conditions were taken into account. The values included in the simulation are showed in Table I.

The determination of these final values of absorption has been made through the adjustment of the simulation results with the parameter values acquired 'in situ'. To achieve this, each material has been assigned absorption coefficients values. Minimum deviations are iteratively applied to these coefficients until the simulated reverberation times (for each frequency) do not differ by more than $10 \%$ from the values measured 'in situ'. This adjustment procedure has proven highly satisfactory [46]. Once the RT curve of the room is adjusted, we compare the results of parameters ( $G, C_{80}$, RASTI and $\left.E D T\right)$ obtained during our simulation for three representative points of the basilica with the values obtained experimentally. Frequency values in octave bands are used for this approach rather than average values. Using information obtained from these comparisons, the coefficients are adjusted until a maximum correlation is obtained between the simulation and architectural reality. There are currently devices that can measure absorptions in situ. Although we have not used these tools, their use should be considered by researchers. However, it is worth noting that their use presents some problems [47].

\subsection{Calculation of parameters}

In accordance with the recommendations of the two simulation programs, the acoustic parameters indicated in point 1.2 were calculated for the 24 receivers. Details of the measurements points are shown in Figure 4. For both programs, an omni-directional source was used for the simulation. Signal type is $105 \mathrm{~dB}$ total output power white noise (94 $\mathrm{dB}$ at $1 \mathrm{~m}$ ) with no emission time delay. The geometric model used in both cases was 1314 surfaces with 30,000 rays emitted. This number of rays has been chosen considering that according to the ray-tracing algorithm, the minimum number to consider is [48]

$$
N_{\min }=\frac{c \cdot t_{\max }^{2}}{r_{k}^{2}},
$$

with $t_{\text {max }}$ being the time of the impulse response and $r_{k}$ the radius of the receptor sphere - equal to 20,000 rays in our case.

To obtain a stable solution in CATT, in addition to a minimum number of rays, it is also necessary to select an adequate truncation time that is greater than the longitude of the impulse response. In EPIDAURE, as indicated in point 3, the order of reflection should be adjusted.

By means of simulation with CATT, the obtained results remain stable when increasing the number of rays or the truncation time of 4.5 seconds. For the simulation with EPIDAURE, the results obtained when varying the number of rays show worsened stability. For an increase of 30.000 to 40.000 a variation of $4 \%$ (less to jnd) for the $T_{30}$ parameter is seen at central frequencies $(50-1000 \mathrm{~Hz})$.

\subsubsection{Calculation times}

Simulating the model of the church using the two programs gives different computing time costs due to the different calculation algorithms used. For the simulation with all 1314 surfaces, 30,000 emitted rays and calculations for the 24 receiver points, CATT-Acoustics gives a processing time of 170 minutes, and EPIDAURE of around 90 minutes. Some simple combinations show that this relation is approximately constant.

\section{Theoretical and experimental results. Discussion}

Nine acoustic parameters, Reverberation Times (TR30 and $E D T)$, Bass Ratio $(B R)$, Brilliance $(B r)$, Clarity $\left(C_{50}\right.$ and 


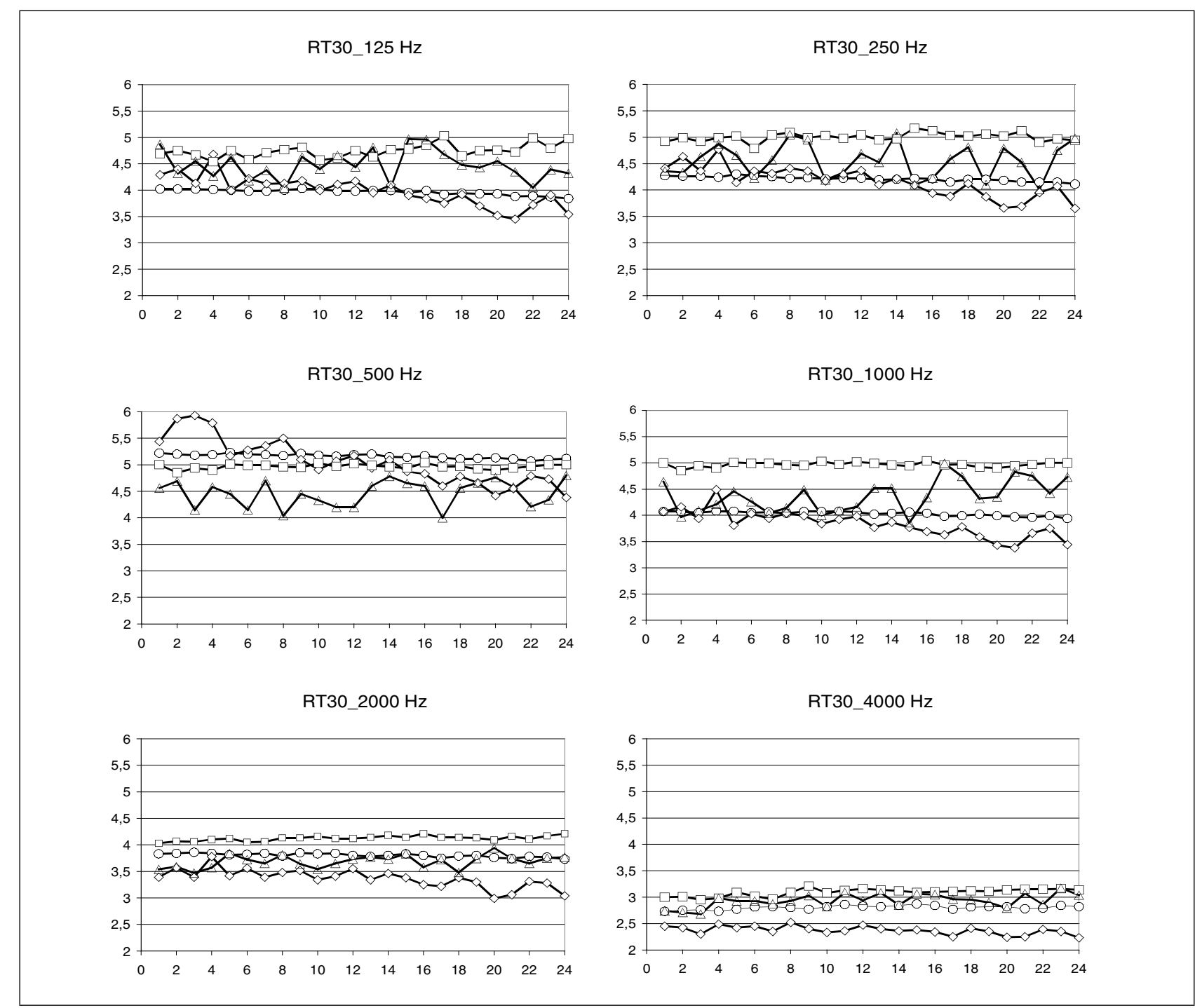

Figure 5. $T_{30}$ (seconds) in octave bands by receiver points. $\square$ WinMLS measurements. $\triangle$ MLSSA measurements. $o$ CATT prediction. $\diamond$ EPIDAURE prediction.

$C_{80}$ ), Center Time $T_{s}$, Strength Factor $G$ and Intelligibility Parameter (STI), were measured using two techniques (MLS and Sweep) and calculated using two simulation programs (EPIDAURE and CATT-Acoustics). The requirements of ISO 3382 Standard were complied with at all times [1].

Comparisons were made between the selected acoustic parameters of reverberation, energy and intelligibility for each of the receiver locations in the room. The results below show: "The variation of each parameter by frequency at all receiver points for measured and calculated values". The variation of the mean values at each receiver point using the two measurement techniques (MLSSA, WinMLS) and the two simulation techniques (EPIDAURE and CATT).

Lastly, to assess the accuracy of the parameter values obtained at each audience point, using the measurementsimulation combination the mean relative error of each parameter by frequency and the mean relative error of the "merit figures" were calculated in just noticeable differ- ence (jnd) units. This comparison will establish whether the results are within the jnd acoustic parameter value. Errors have been determined for mean values of the 4 possible measurement-simulation combinations: CATTMLSSA, CATT-WinMLS, EPIDAURE-MLSSA and EPIDAURE-WinMLS. The obtained results are presented below, and a more detailed discussion of these results is included in section five.

\subsection{Result of measurement and calculation. Varia- tion according to frequency and position}

Figures 5 to 8 show the representation by frequencies of the different parameters in all the measurement locations.

\subsubsection{Reverberation parameters}

Figures 5 and 6 show the variation of the reverberation parameters according to frequency and position. The values of the $E D T$ and $T_{30}$ parameters follow a sufficiently clear tendency. If we look at the $T_{30}$ graphs, we can see that in general terms the simulation method gives lower values 
EDT_125 Hz

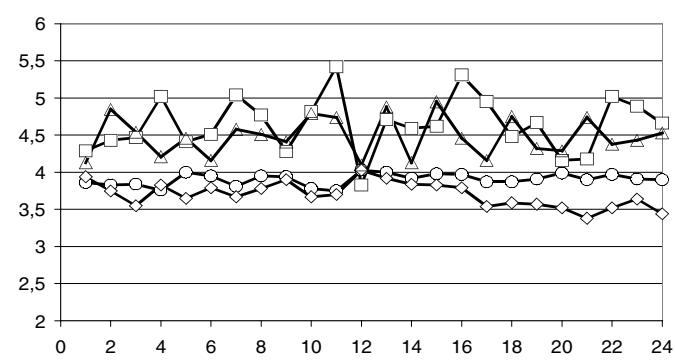

EDT_500 Hz

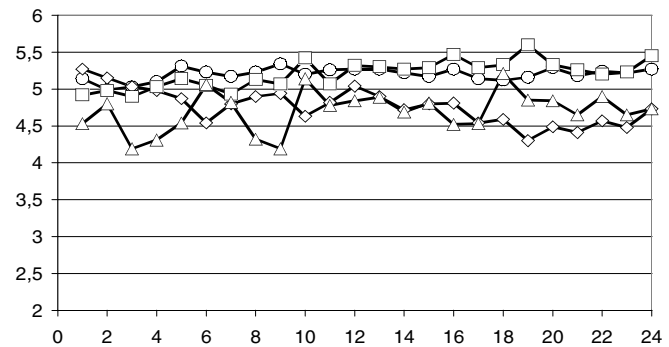

EDT_2000 Hz

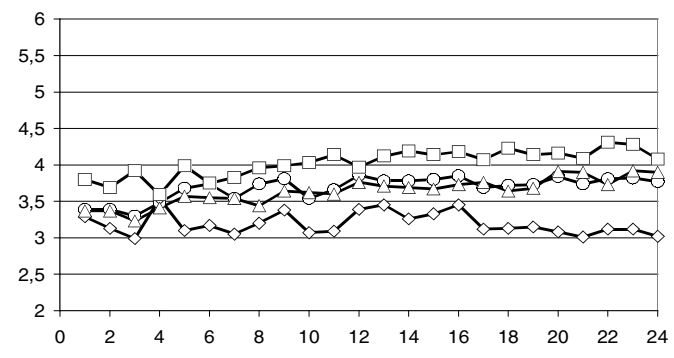

EDT $250 \mathrm{~Hz}$

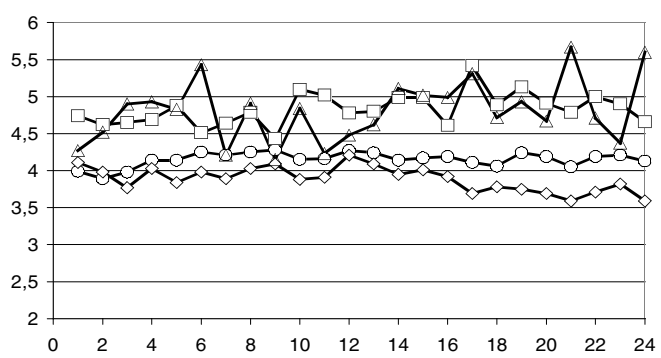

EDT_1000 Hz

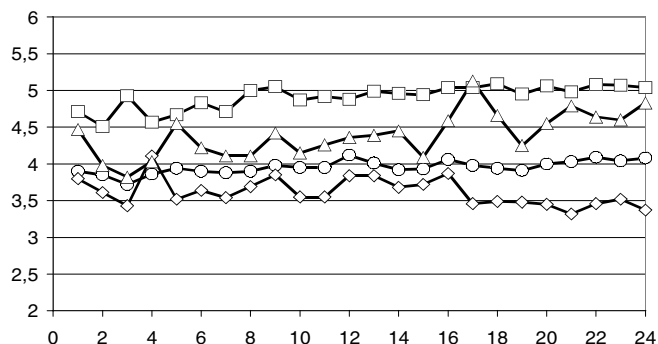

EDT_4000 Hz

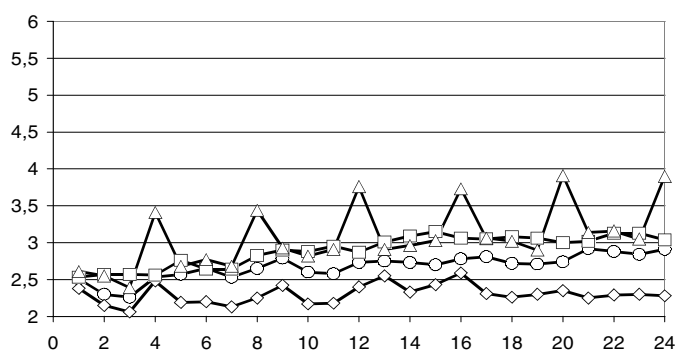

Figure 6. EDT (seconds) in octave bands by receiver points. $\square$ WinMLS measurements. $\triangle$ MLSSA measurements. $o$ CATT prediction. $\diamond$ EPIDAURE prediction.

than the measurement method (inside the limits of variation of the frequency average as specified in 3.2). Calculation with EPIDAURE gives lower simulation values, whilst the highest values are obtained with WinMLS measurements. The only exception to this occurs at the frequency of $500 \mathrm{~Hz}$. At this frequency, the value measured with MLSSA is usually the lowest, and for the points closest to the source the highest values are given by EPIDAURE, whilst for medium and long distances CATT gives the highest values. The values modelled with CATT and those measured with WinMLS are very similar. In a similar way to that observed with $T_{30}$, in general the modelled $E D T$ values are lower than the measured ones. EPIDAURE gives the lowest values, although once again with the exception at $500 \mathrm{~Hz}$. For low frequencies (125 to $250 \mathrm{~Hz}$ ), the measured values show great spatial variability depending on the location of the measurement point (possibly due to scattering elements such as columns and ornaments), but however they match in both measurement procedures. At $1000 \mathrm{~Hz}$ and $2000 \mathrm{~Hz}$, WinMLS gives the highest values. At $4000 \mathrm{~Hz}$, we can see a particularly high variation phenomenon with MLSSA measurement. This means that the signal emitted is a significant factor for this frequency and in this geometry. It is interesting to note that in this case, the CATT prediction value and the WinMLS measured value match closely.

\subsubsection{Energy parameters}

Figures 7 to 9 show the variation in energy parameters according to frequency. As we can see in all the graphs (see Fig. 7), they are parameters which display similar positional variability in the two measurements made and in the two modelling calculation procedures. Furthermore, we can see that the variability in modelling is very similar to the variability in measurement. In general, the highest value is obtained with EPIDAURE, and the lowest value for mid and high frequencies is obtained with WinMLS measurement. The exception occurs at $125 \mathrm{~Hz}$; here the lowest value is that obtained with MLSSA measurement.

Something similar to that which occurs for the $C_{80}$ parameter can be observed in the $C_{50}$ graphs (see Figure 8). In general, the lowest values are obtained with WinMLS 


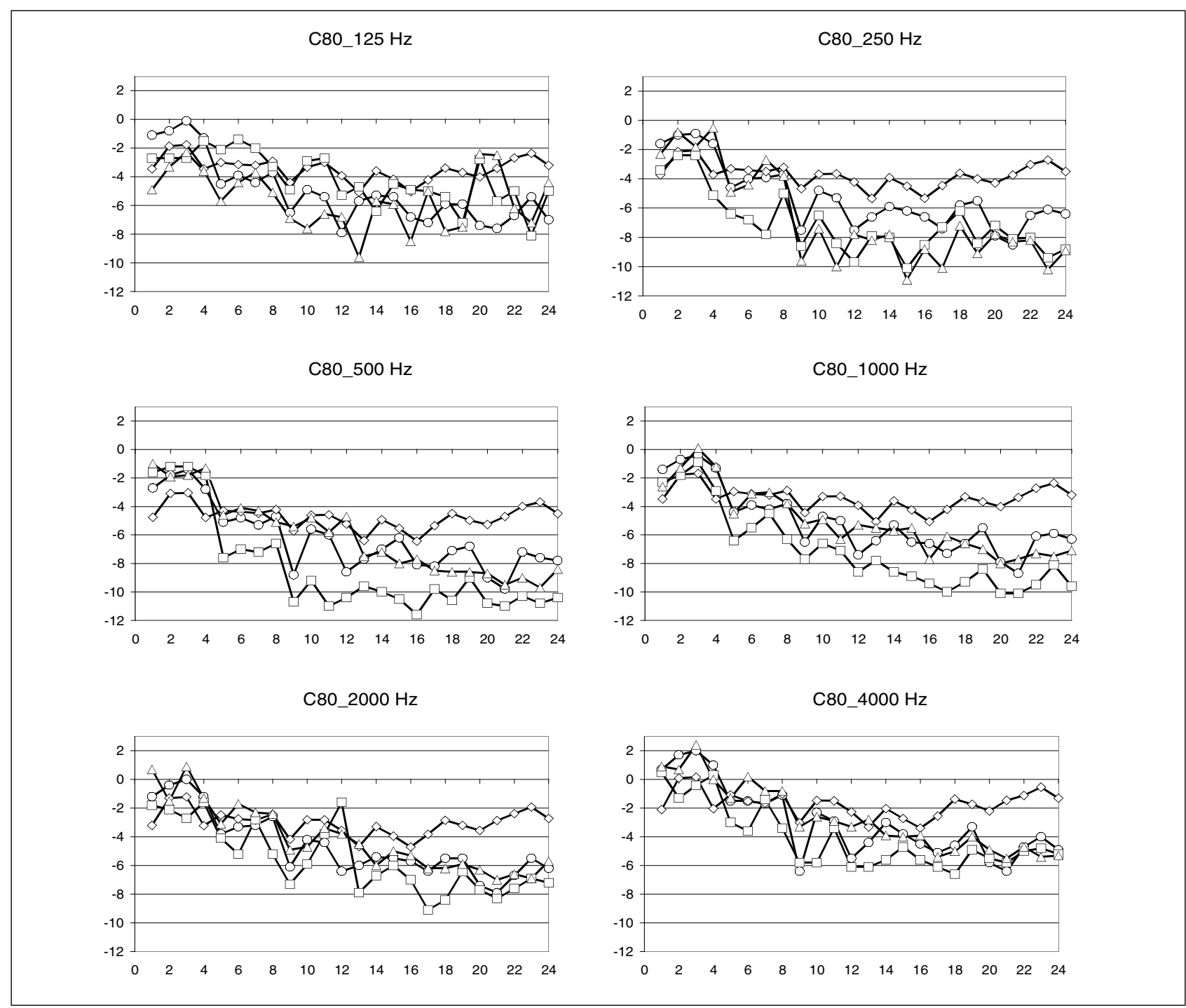

Figure 7. $C_{80}(\mathrm{~dB})$ in octave bands by receiver points. $\square$ WinMLS measurements. $\triangle$ MLSSA measurements. $o$ CATT prediction. $\diamond$ EPIDAURE prediction.

measurements and the highest with EPIDAURE prediction. Exceptions are at low frequencies. At $125 \mathrm{~Hz}$ and $250 \mathrm{~Hz}$, MLSSA gives the lowest values. At $125 \mathrm{~Hz}$, WinMLS gives the highest values and at $250 \mathrm{~Hz}$, EPIDAURE gives the highest values.

We can conclude that the tendency of the different clarity parameters is similar. In $C_{80}$, the tendencies stay similar in the four cases. In $C_{50}$, larger differences are observed, probably due to the fact that the volume of the room means that the definition calculation (linked to $C_{50}$ ) is a value which fluctuates according to position, with speech values which are not adequate.

In the case of the $T_{s}$ parameter measured and calculated in all the mid-range bands (Figure 9), it can be seen that there is a variation according to where the measurement or sampling is carried out. In general, the value measured with WinMLS is the highest. MLSSA and CATT are very similar except at low frequencies, where the MLSSA results show high positional variability. EPIDAURE gives very low and practically constant values at around $200 \mathrm{~ms}$, relative to the measured values and the value modelled using CATT. The CATT calculation fits the tendencies given by measurement.

Previous research [49] shows a similar result to the one we observe as regards the values of $T_{s}, C_{80}$ and $C_{50}$. The predicted $T_{s}$ value is usually lower than the measured value (particularly with EPIDAURE). This suggests that the effects of late reflections are not well handled by the simulation algorithms. This matches the fact that the predicted values for $C_{50}$ and $C_{80}$ are higher than the measured values. (The programs have under-estimated the statistical tail correction of impulse response).

\subsection{Measurement and simulation mean values. Variation according to position}

Calculating the mean values of parameters by position gives an interesting assessment of the room response for the selected receivers. The following figures (Figures 1012) show the value of the different parameters for the 24 receiver positions. 
C50_125 Hz

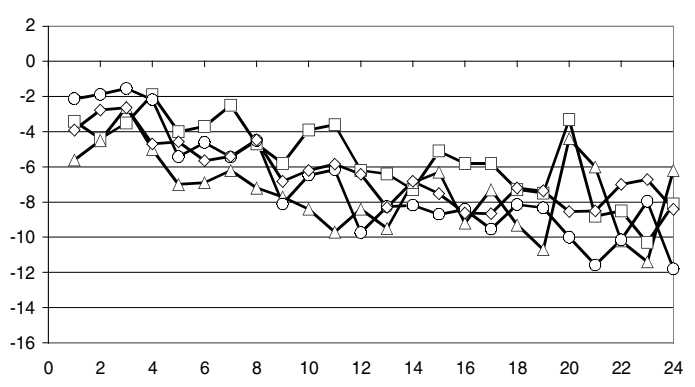

C50_500 Hz

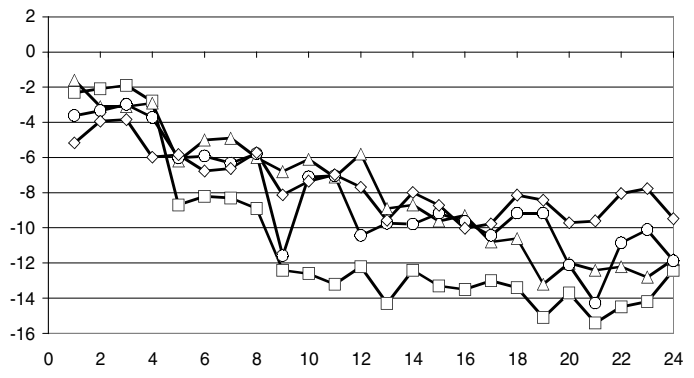

C50 $2000 \mathrm{~Hz}$

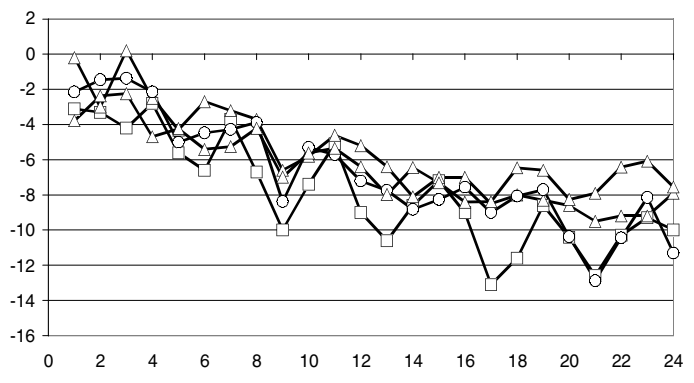

C50_250 Hz

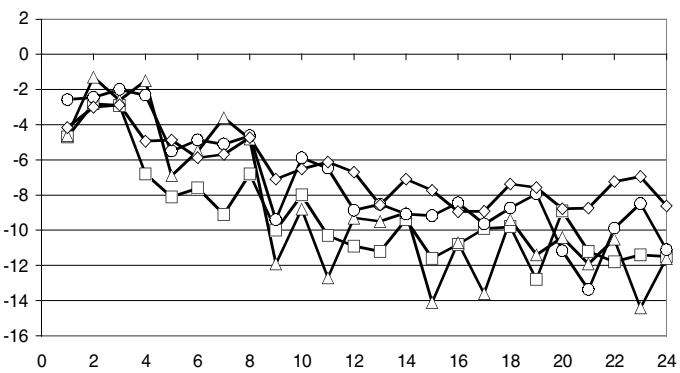

C50_1000 Hz

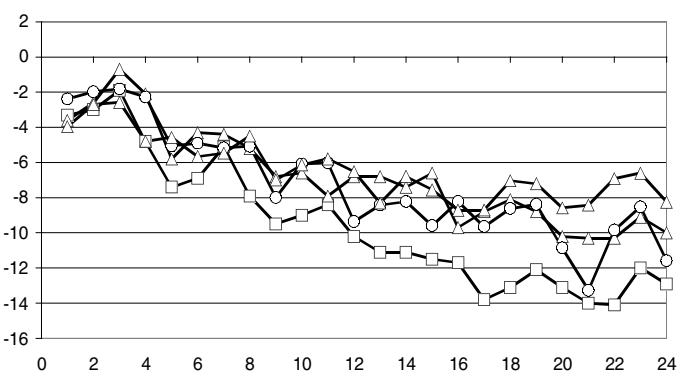

C50 $4000 \mathrm{~Hz}$

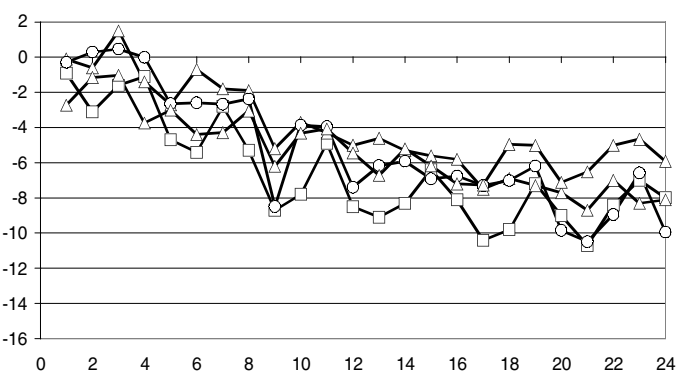

Figure 8. $C_{50}(\mathrm{~dB})$ in octave bands by receiver points. $\square$ WinMLS measurements. $\triangle$ MLSSA measurements. $o$ CATT prediction. $\diamond$ EPIDAURE prediction.

\subsubsection{Reverberation parameters}

As can be expected when working with the mean values of reverberation parameters, positional variability decreases. Moreover, the differences between modelled and measured values also decrease. The highest values for $E D T_{\text {mid }}$ and $T_{30 \text {,mid }}$ are obtained from the WinMLS measurements. For EDT, the lowest value is obtained with the EPIDAURE calculation. For $T_{30}$, the lowest values for the closest points to the source are obtained with the MLSSA measurements, and for the points furthest away these are given by the EPIDAURE prediction.

For Brilliance $(\mathrm{Br})$, the highest value is given by MLSSA and the lowest by EPIDAURE. There is an error between CATT and WinMLS, which is quite pronounced between MLSSA and EPIDAURE. For warmth or BASS RATIO $(B R)$, the highest value is given by MLSSA and the lowest by CATT prediction.

Analysis of results for the measurement-calculation combination shows greater stability in the values obtained by CATT and WinMLS for $E D T_{\text {mid }}$ and $T R 30_{\text {mid }}$ relative to position. For $\mathrm{Br}$ there is very little error between CATT and WinMLS, but it is quite pronounced in the comparison between MLSSA and EPIDAURE. For $B R$, the differences between the two aforementioned pairings are slightly more noticeable.

\subsubsection{Energy parameters}

The positional variation with the mean values of $C_{80}, C_{50}$ and $T_{S}$ is still present. Measurement tendencies are similar. The lowest values for clarity parameters are given by WinMLS, with greater scattering for points further away. This greater difference with distance is also seen in the calculations using the two simulation programs, the results obtained with EPIDAURE being higher. (The lower $T_{s}$ values obtained with EPIDAURE are translated into an increase in $C_{80}$ and $C_{50}$ due to the handling of late reflections by the calculation algorithms). For the mean $G$ values $(500-1000 \mathrm{~Hz})$, there is good correspondence between the measured values and the simulated values, and likewise with their tendency according to position. The difference between measured values and calculated values increases with position, which we believe is due to the han- 


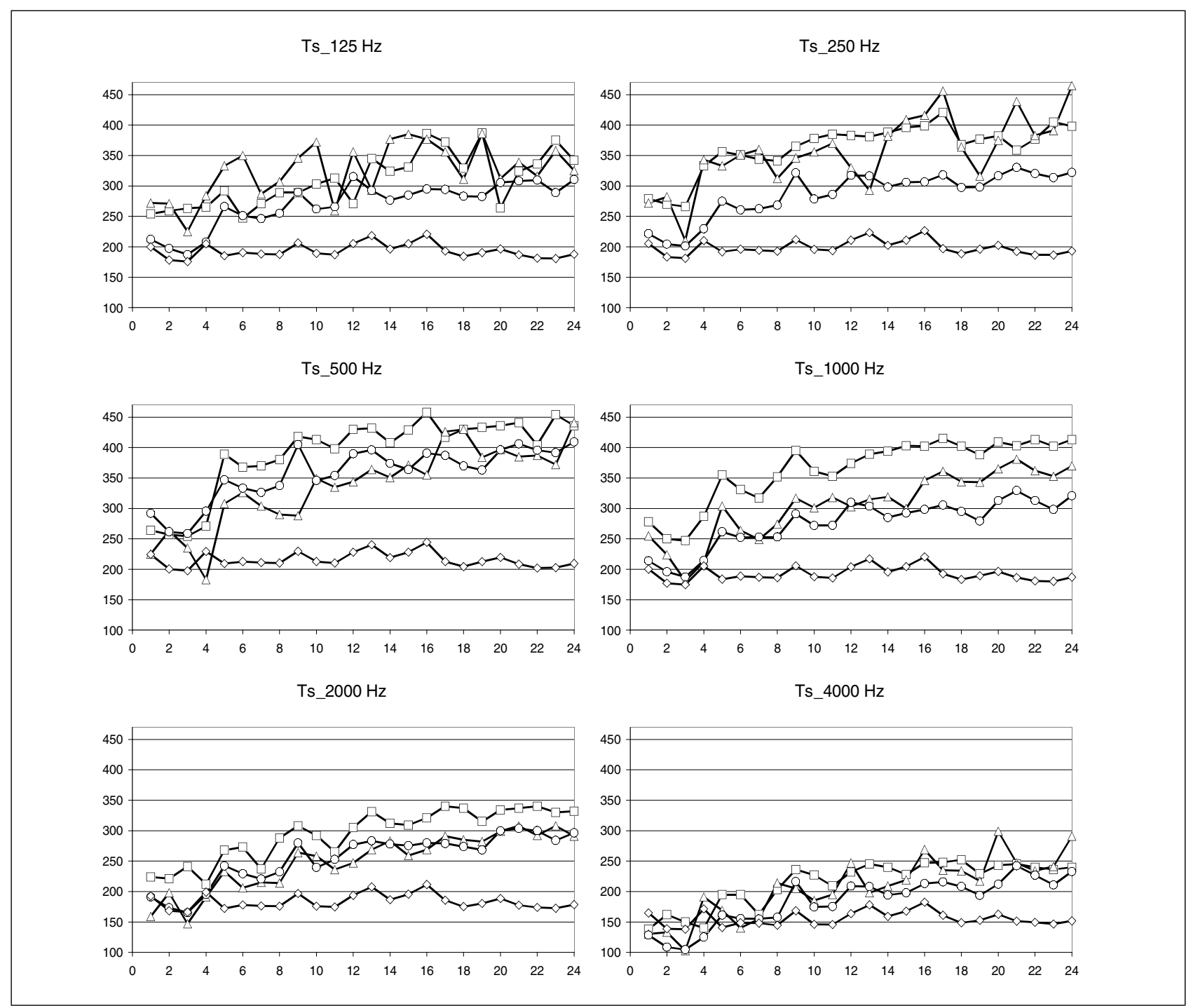

Figure 9. $T_{s}(\mathrm{~ms})$ in octave bands by receiver points. $\square$ WinMLS measurements. $\triangle$ MLSSA measurements. $o$ CATT prediction. $\diamond$ EPIDAURE prediction.

dling of the late reflections by the simulation calculation algorithms.

\subsubsection{Intelligibility parameters}

The STI also follows a similar tendency in all four cases. In general, the lowest value is given by WinMLS measurements. The highest value for points further away is given by EPIDAURE prediction, whilst the highest values for points close to the source are given by CATT prediction and MLSSA measurements (see Figure 12).

\subsection{Assessment of measurement-simulation accu- racy}

To characterize the acoustic properties of rooms in which hearing (of speech or music) is a significant consideration, the mean frequency and space values of the acoustic parameters, the so-called "merit figures", are used. The results are presented in sections 4.1 and 4.2. Variation in the values of the different acoustic parameters (measurement and calculation accuracy), will be more acceptable the closer it is to the smallest different in sensation that a hearer can perceive, termed in psycho-physics the "just noticeable difference", (jnd). Study of the sensitivity of the hearer to changes in the sound field has been an important area of research over the last 50 years [50, 25, 11, 17] and has given rise to the establishment of these indicators (jnd), which are on the whole accepted by the scientific community (see Table refJND). These values, whose relationship to frequency has not been established, have greater validity at $1000 \mathrm{~Hz}$ and for mean values [23]. They establish the accuracy with which parameters should be measured, and the accuracy of calculation by means of modelling software. The relative error values of parameters for each measurement-simulation technique between the thresholds of the associated jnd's are a good approximation for studying the acoustic quality of rooms.

In this work, the relative errors for each parameter by frequency have been determined for the mid-range frequencies $(125 \mathrm{~Hz}-4 \mathrm{kHz})$, and the mean relative error for the "merit figures". This analysis was carried out 


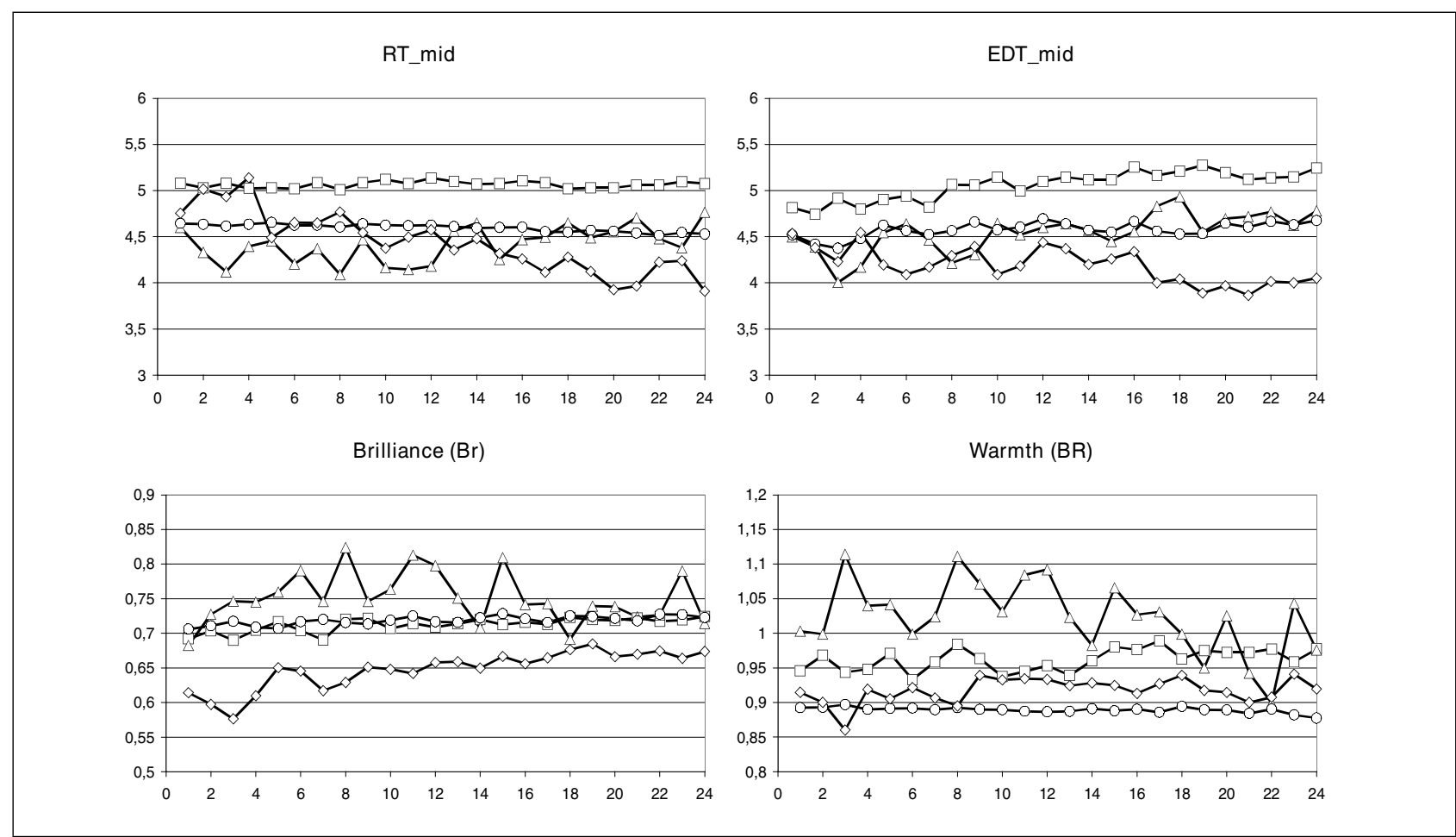

Figure 10. Measurement and simulation mean values of $T_{30}$ (s), EDT (s), $B r$ and $B R$ at 24 receiver points. $\square$ WinMLS measurements. $\triangle$ MLSSA measurements. $o$ CATT prediction. $\diamond$ EPIDAURE prediction.

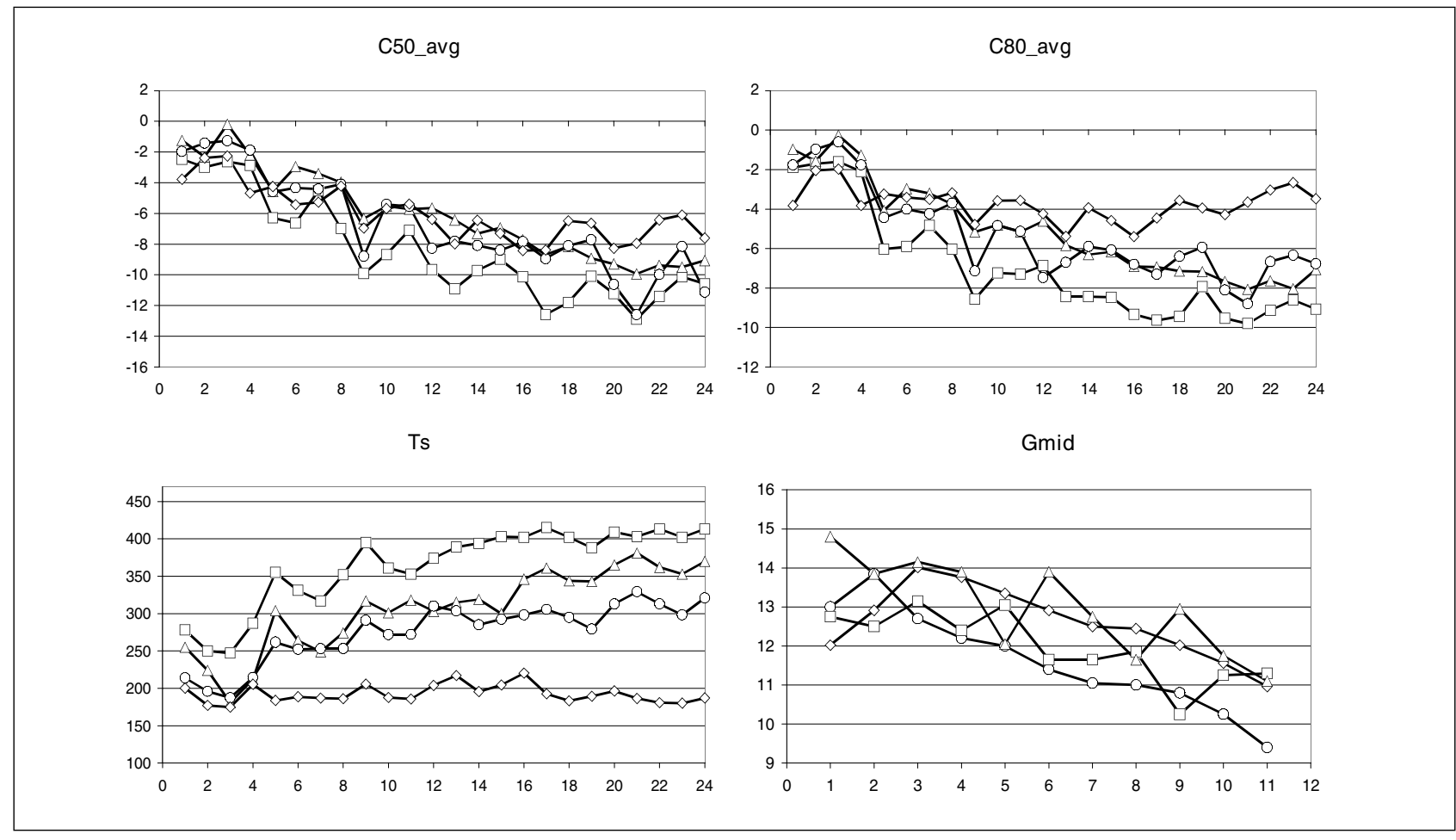

Figure 11. Measurement and simulation mean values of $C_{50}(\mathrm{~dB}), C_{80}(\mathrm{~dB}), T_{s}(\mathrm{~ms})$ and $G(\mathrm{~dB})$ at 24 receiver points. $\square$ WinMLS measurements. $\triangle$ MLSSA measurements. $o$ CATT prediction. $\diamond$ EPIDAURE prediction.

for the 4 possible measurement-simulation combinations: CATT-MLSSA, CATT-WinMLS, EPIDAURE-MLSSA and EPIDAURE-WinMLS. By comparing these errors, the trueness of each technique is analyzed.
The calculation of this relative error compared with the parameter jnd is obtained from the expressions 13, for reverberation parameters, and 14 for energy parameters and intelligibility parameters [11]. These errors are determined 


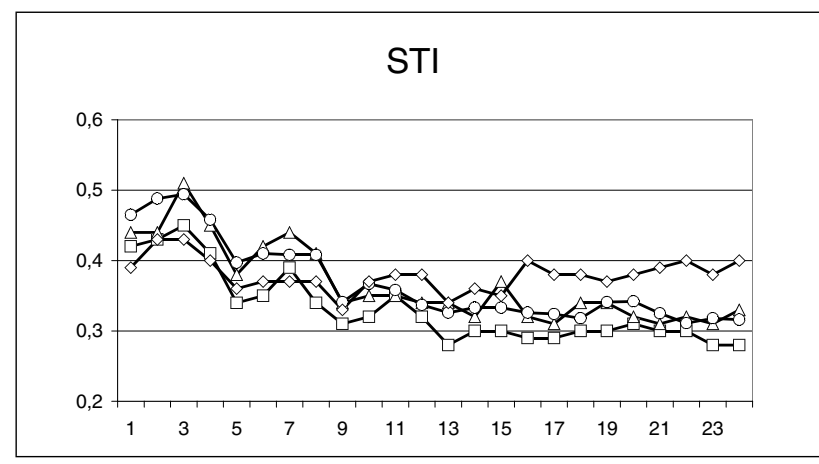

Figure 12. Measurement and simulation mean values of STI at 24 receiver points. $\square$ WinMLS measurements. $\triangle$ MLSSA measurements. $o$ CATT prediction. $\diamond$ EPIDAURE prediction.

Table II. Room acoustics parameters and their associated jnd's.

\begin{tabular}{|c|c|}
\hline Parameter & jnd \\
\hline$T_{30}(\mathrm{~s})$ & $5 \%$ \\
$E D T(\mathrm{~s})$ & $5 \%$ \\
$C_{50}, C_{80}(\mathrm{~dB})$ & $1 \mathrm{~dB}$ \\
$T_{s}(\mathrm{~ms})$ & 10 \\
$G$ & $1 \mathrm{~dB}$ \\
\hline
\end{tabular}

for mean parameter values by frequency at the 24 receiver points (Figure 13), and for the 'merit figures' values (Figure 14).

$$
\begin{aligned}
& E=\sum \frac{\left|P_{\text {measured }}-P_{\text {simulated }}\right| \cdot 100}{N_{\text {pos }} \cdot P_{\text {measures }} \cdot j n d}, \\
& E=\sum \frac{\left|P_{\text {measured }}-P_{\text {simulated }}\right| \cdot}{N_{\text {pos }} \cdot j n d},
\end{aligned}
$$

where $P_{\text {measured }}$ is the value of the measured parameter, $P_{\text {simulated }}$ is the value of the simulated parameter, $N_{\text {pos }}$ is the number of measurement positions and jnd is the smallest difference for the parameter that the receiver can detect.

In Figure 13, when we look at the relative errors of the parameters by frequency with respect to the corresponding jnd's, we can see that in almost all cases the error is below 5 jnd units, values which are similar to those obtained by [11] in his study of 11 concert halls, and within the variability shown by the parameters in each hall [15]. This means that the discrepancies between the predicted values and the measured values barely reach 5 jnd for all 4 possible measurement-simulation combinations, this value being the threshold for what a hearer is able to perceive. The least satisfactory results are for $T_{s}$. In the comparison of the EPIDAURE predicted values with the WinMLS measured values, the relative error is nearly $20 \mathrm{jnd}$. This means that from the design perspective, $T_{s}$ is the least suitable parameter to use in these types of room. This behavior is the same as that observed with the mean parameters shown in Figure 14. All the deviations are below $5 \mathrm{jnd}$, except for $T_{s}$ (for the value at $1000 \mathrm{~Hz}$ ).

\section{Conclusions}

Two measurement techniques (MLSSA and WinMLS) which use different excitation signals (MLS and Sweep) and two geometric simulation techniques (EPIDAURE and CATT) were used to obtain, by means of measurement and calculation, the acoustic parameters in a church with complex geometry. These experimental and simulated values were analyzed by frequencies and in mean values by means of "merit figures". The relative errors of the parameters with respect to jnd were determined.

It is difficult to arrive at general conclusions regarding the presented strategy and data since only one room is discussed using a single ray-tracing/cone-tracing algorithms. However, we will present some conclusions that may help the practitioner/reader when approaching the problem of simulation, parameters calculation, measurement, and comparison:

Simulation Although it has not been object of study in this work, it is evidence that choosing the geometric model and materials, selecting the number of appropriate surfaces in the room, and the appropriate acoustic characteristics of the materials, are the first and costly tasks that must be carried out. Starting from this model, the minimum number of rays is determined by the reverberation time (see section 12).

When working with CATT, the number of rays and truncation time should be chosen. The minimum truncation time (of the order of $T_{30}$ ) is determined by the longitude of the impulse response.

For EPIDAURE, the number of rays and reflection order should be selected. It is necessary to vary the number of the order of reflection until arriving at a stable accuracy solution. Specific values cannot be indicated because these depend on the characteristics of the room. The fundamental aim of the simulation is to obtain a stable value for the parameters.

The CATT calculation time is approximately twice as long as EPIDAURE when using the same number of rays and a truncation time of 4.5 seconds with an order of reflection of 10 .

Measurements It is very important to use homologated equipment that complies with standardized technical requirements. When making the measurements, a correct signal-to-noise ratio should be ensured. To achieve this, the choice of the transmitted signal is very important: type, level, and duration.

Parameters calculation The same algorithms have been used for determining the parameters of the measurements because they have always been calculated with WinMLS. It is worthwhile noting that various researchers [51, 52] have shown that different calculation algorithms can produce significantly different values. This could explain the differences between the values obtained using measurements and simulations. This factor would be worth studying because the $T_{S}$ shows the greatest variability between the measured and simulated values (WinMLS and EPIDAURE). Un- 

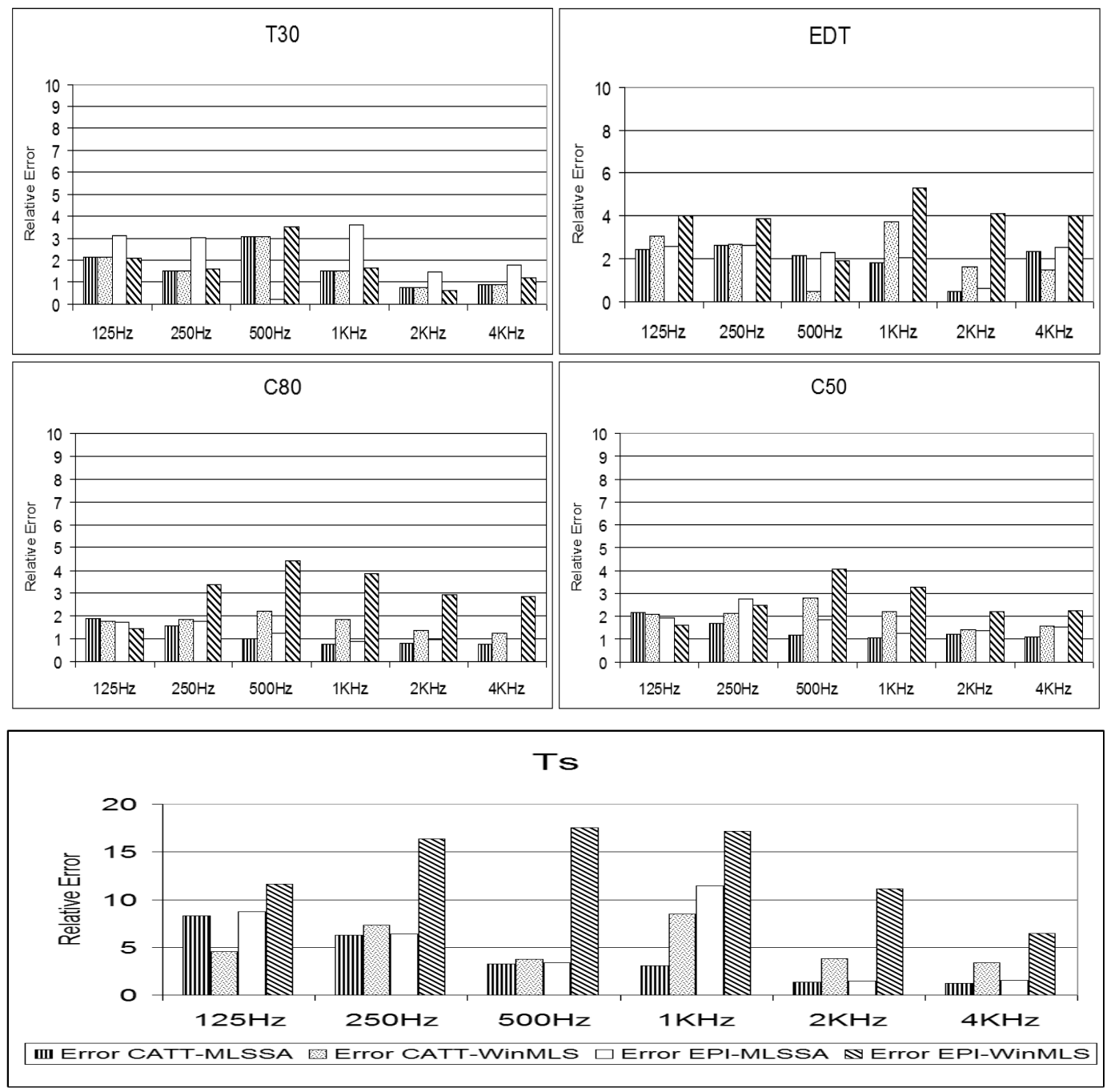

Figure 13. Relative errors expressed in jnd units for the mean values of parameters by frequencies at the 24 receiver points for the different measurement and simulation techniques.

fortunately, EPIDAURE does not provide IRs, and this prevents us from studying whether this difference in $T_{S}$ values is because the calculation algorithms are different.

However, the fact that in some cases, the difference between values obtained with EPIDAURE and those measured with MLSSA do not greatly differ leads us to believe that the calculation algorithm will not enable us to entirely explain the mentioned differences - and its cause must be found in other factors of the transmission-reception system. It is worth noting that signal transmission and data acquisition cards are the only measurement processing elements that are different for WinMLS and MLSSA.

Bearing in mind that the acquisition card is standard, we suggest that the origin of the differences is in the excitation signal. We intend to research this more closely by selecting an adequate excitation signal. However, this is an objective that is outside of the scope of this work.

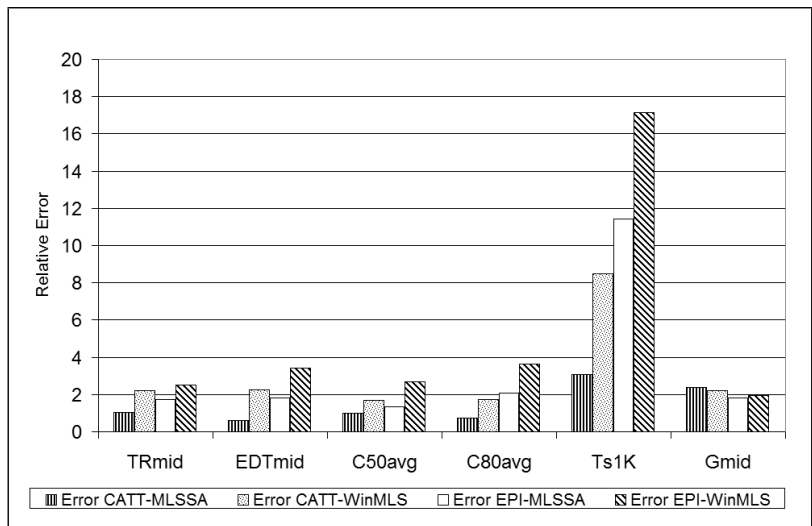

Figure 14. Relative errors expressed in jnd units for the mean values of the "merit figures" at the 24 receiver points for the different measurement and simulation techniques.

Modelling room acoustics If the aim of the reader/practitioner is to make a comparison between modelled and 
measured parameters then the following must be carried out: an appropriate distribution of the measuring points, an appropriate simulation of source and receivers; and an adjustment for the acoustic characteristics of the materials (reverberation with a deviation no greater than $10 \%)$. It is then worthwhile making a fine adjustment by comparing other parameters $\left(\mathrm{G}, C_{80}\right.$, RASTI, and $E D T)$. The final validation of the model can be made using errors relative to the jnds.

When using prediction for the energy parameters, there are differences between the results obtained by frequencies and the results by mean values. The jnd errors for mean values are lower than the values by frequency. This justifies working with mean values when quantifying the acoustic features of rooms. Nevertheless, the exclusive use of these types of simplification can lead to design flaws since, as we saw with the calculation of accumulated errors for all the measurement points, these can be large, viz. here the case of $T_{s}$.

In general, the differences between the simulated values and the measured values for all parameters, both by frequency and mean values, increase with distance.

\section{Acknowledgement}

This study has been supported with FEDER funds, The Spanish Ministry of Science and Innovation also helped supporting the present study in a Coordinated Investigation Project Framework (references BIA2003-09306-C04 and BIA2008-05485).

We would like to thank the Rector and the Chapel Master of the Saint James' Basilica in Algemesí for allowing us to access to the church and for their collaboration in the measurements.

The translation of this paper was funded by the Universidad Politécnica de Valencia, Spain.

\section{References}

[1] ISO3382:1997: Acoustics. Measurement of the reverberation time of rooms with reference to other acoustical parameters. International Organization for Standardizacion (ISO), 1997.

[2] E. Thompson: Dead rooms and live wires; Harvard, Hollywood, and the deconstruction of architectural acoustics, 1900-1930. Isis 88 (1997) 597-626.

[3] J. H. Rindel: Modelling in auditorium acoustics- from ripple tank and scale models to computer simulations. No. Especial de la Revista de Acústica (CD-Rom), Forum Acusticum, Sevilla, 2002, 32 keynote lecture.

[4] J. H. Rindel: The use of computer modeling in room acoustics. J. Vibro. Eng. 3 (2000) 41-72.

[5] T. Yokota et al.: Comparison of room impulse response calculated by the simulation methods based on geometrical acoustics and wave acoustics. Proceedings 18th International Congress on Acoustics, Kyoto, Japan, 2004.

[6] A. Krokstad, S. Strom, S. Sorsdal: Calculating the acoustical room response by the use of a ray tracing technique. J. Sound Vib. 8 (1968) 118-125.
[7] M. Vorländer: Simulation of the transient and steady-state sound propagation in rooms combined ray tracing/imagesource algorithm. J. Acoust. Soc. Am. 86 (1989) 172-178.

[8] M. Vorländer: International Roun Robin on room acoustical computer simulation. Proceedings 15 th International Congress on Acoustic, Trondheim, Norway, 1995, 577580.

[9] M. J. Howarth, Y. W. Lam: An assessment of the accuracy of a hybrid room acoustics model with surface diffusion facility. Appl. Acoust. 60 (2000) 237-251.

[10] I. Bork: A comparison of room simulation software. The 2nd Round Robin an room acoustical computer simulation. Acustica united with Acta Acustica 86 (2000) 943-956.

[11] J. H. Rindel et al.: Comparisions between computer simulations of room acoustical parameters and those measured in concert halls. Joint meeting of the Acoustical Society of America and the European Acoustics Association, 1999.

[12] Y. W. Lam: A comparison of tree diffuse reflection modelling methods used in room acoustics computers models. J. Acoust. Soc. Am. 100 (1996) 2181-2192.

[13] M. Vorländer et al.: Definition and measurement of random-incidence scattering coefficients. Applied Acoustics 60 (2000) 187-199.

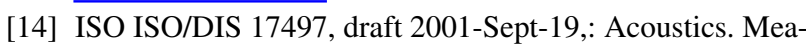
surement of sound scattering properties of surfaces. Part 1: Measurement of the random-incidence scattering coefficient in a reverberation room. 2001.

[15] L. N. Yang, B. M. Shield: Development of a ray tracing computer model for the prediction of the sound filed in long enclosures. Journal of Sound and Vibration 229 (2000) 133-146.

[16] P. D'Antonio, T. J. Cox: The use of coded signals in the measurement of diffusing surfaces. J. Acoust. Soc. Am. 124 (2008) 2473.

[17] H. Shiokawa, J. H. Rindel: Comparisions between computer simulations of room acoustical parameters and those measured in concert halls. Institute of Industrial Technology, Nihon University, 2007.

[18] R. San Martin: Accuracy in the measurement of parameters derived from impulse response in room acoustics. University of Navarre, 2008.

[19] CATT: CATT-Acoustic v8. user's manual: Room acoustic prediction and desktop auralization. 2002.

[20] C.S.T.B., Epidaure: Prediction of auditorium acoustics. User's manual. Version 1.0. 0'1 dB, 1994.

[21] WINMLS: Morset Sound Development. WinMLS 2004. Reference manual. 2004.

[22] D. R. Douglas: MLSSA: Maximum length sequence system analyzer. Reference manual. DRA Laboratories (http:// www.mlssa.com), 2005.

[23] T. J. Cox et al.: The sensitivity of listeners to early sound field changes in auditoria. Acustica 79 (1993) 27-41.

[24] J. S. Bradley et al.: A just noticeable difference in C50 for speech. Applied Acoustics 58 (1999) 99-108.

[25] M. Vorländer: International roun robin on room acoustical computer simulation. Proceedings 15th International Congress on Acoustics, Trondheim, Norway, 1995, 689692.

[26] R. Höhne et al.: Zur Wahrnehmbarkeit von Deutlichkeitsund Durchsichtigkeitsunterschieden in Zuhörersälen (The visibility of definition and clarity parameters in concert halls). Acustica 81 (1995) 309-319. 
[27] I. B. Witew: Is the perception of listener envelopment in concert hall affected by clarity? Proc. DAGA`06, Braunschweig, Germany, 2006.

[28] D. de Vries et al.: Spatial fluctuations in measures for spaciousness. J. Acoust. Soc. Am. 110 (2001) 947-954.

[29] J. Segura et al.: Saint James church acoustic study for the installation of a pipe organ. 6th International Conference on Auditorium Acoustics. Proceedings of the Institute of Acoustics, 2006.

[30] Official State Bulletin: Royal Decree 3028 of November 16 1979. (http://www.boe.es), 1980.

[31] S. Cerdá et al.: Room acoustical parameters: a factor analysis approach. Applied Acoustics 70 (2009) 97-109.

[32] A. Giménez: Contribution to the study of acoustics in closed rooms. Application to concert halls. Universitat Politécnica de Valencia, 1989.

[33] A. Giménez, A. Marín: Analysis and assessment of concert halls. Applied Acoustics 25 (1988).

[34] L. Beranek: Concert hall and opera houses. Springer Verlag, New York, 2004.

[35] Y. Ando: Concert hall acoustics. Springer, Berlin, 1985.

[36] M. Barron: Auditorium acoustics and architectural design. EFN Spon, London, 1993.

[37] A. Gimenez et al.: Estudio de la evolucion de parametros acusticos que miden la calidad de salas de conciertos. TecniAcústica, La Rioja, 2001.

[38] M. Barron: Subjective study of British symphony concert halls. Acta Acustica 66 (1988) 1-14.

[39] G. L. Marshall: An acoustics measurement program for evaluating auditoriums based on the early/late sound energy ratio. J. Acoust. Soc. Am. 96 (1994).

[40] R. Kürer: Einfaches Messverfahren zur Bestimmung der Schwerpunktzeit raumakustischer Impulsantworten (Simple measuring procedure for determining the center time of room acoustical impulse responses). 7th International Congress on Acoustics, Budapest, 1971.
[41] T. Houtgast, H. J. M. Steeneken: A review of the MTF concept in room acoustics and its use for estimating speech intelligibility in auditoria. J. Acoust. Soc. Am. 77 (1985) 1069-1077.

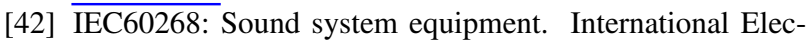
trotechnical Commission.

[43] L. M. Wang: The influence of absorption factors on the sensitivity of to virtual room's sound field to scattering coefficients. Applied Acoustics 69 (2008) 1249-1257.

[44] H. Kuttruff: A simple iteration scheme for the computation of decay constants in enclosures with diffusely reflecting boundaries. J. Acoust. Soc. Am. 98 (1995) 288-293.

[45] T. Lentz et al.: Virtual reality systemwith integrated sound field simulation and reproduction. Hindawi Publishing Corporation. EURASIP Journal on Advances in Signal Processing, 2007.

[46] M. Galindo et al.: Measured acoustics parameters versus predicted ones in two Gothic-Mudejar churches. Forum Acusticum, Sevilla, 2002.

[47] C.-H. Jeongb: Non-uniform sound intensity distributions when measuring absorption coefficients in reverberation chambers using a phased beam tracing. J. Acoust. Soc. Am. 127 (2010) 3560-3568.

[48] J. S. Suh, P. A. Nelson: Measurement of transient response of rooms and comparison with geometrical acoustic models. J. Acoust. Soc. Am. 105 (1999).

[49] R. San Martín, M. Arana: Predicted and experimental result of acoustic parameters in the new Symphony Hall in Pamplona, Spain. Applied Acoustics 67 (2006) 1-14.

[50] W. Reichardt, W. Schmidt: The detectability of changes in sound field parameters for music. Acustica 18 (1967) 274 282.

[51] B. F. G. Katz: International round robin on room acoustical impulse response analysis software 2004. ARLO 5 (2004) $158-164$.

[52] I. B. Witew et al.: Uncertainties in measurement of single number parameters in room acoustics. Proc. Forum Acusticum, Budapest, Hungary, 2005. 